\section{ENUCLEATION OF A UTERINE FIBROMA BETWEEN THE SECOND AND THIRD STAGES OF LABOUR.}

\section{BY J. FARRANT FRY, L.R.C.P. LOND.,} ASSISTANT-SURGEON TO THE SWANSEA MOSIיTTAL.

Mrs. E- aged twenty-nine, a strongly built woman, was married at twenty, and had been pregnant eight times with the following result:-1. A seven-and-a-half months' stillborn child. 2 and 3. A miscarriage at the sixth week. 4. A seven-and-a-half months' stillborn child. 5. A full-time female living child, after twenty-four hours' natural labour (this was in 1875). 6. A full-time female living child after thirty-six hours' labour (delivered by forceps). 7. A third full-time female living child after sixty hours' labour (delivered by forceps; this was in 1879). A few days after this confinement a hard swelling the size of a cocoanut came down whilst she was sitting on the chamber. She caught hold of it with her hands and tried to drag it away, but her doctor, coming in sent her back to bed, and took no notice of what she told him had occurred. 8. In November, 1880 she was attended by two doctors, who found a large tumour attached to the anterior lip of the cervix, and who, with considerable difficulty, delivered, by turning, a full-time stillborn female child, A few months after this the patient was placed under chloroform and a portion of the tumour removed with the wire écraseur, but, being sessile, it was impossible to take it all away. Prior to this her periods had always been regular and natural, but since the operation she had constant hæmorrhage. On May 16th, 1882, she first came under my care, though I had been present and had examined her at the operation. She was pregnant, and almost at full term. On vaginal examination I found a large smooth tumour attached by a broad base to the inside of the anterior lip of the cervix. It was of the size of a small foetal head, and almost filled the pelvic inlet; the posterior lip was stretched like a valve over the centre of the tumour, and no membranes or presentation could be felt; indeed the hand had to be passed into the vagina to reach the interval between the tumour and the posterior lip. With difficulty a gum elastic eatheter was passed into the uterus at 5 P.M. on May 16th. Increasingly strong pains followed, and in twenty four hours, by passing the hand into the vagina, the os could be easily dilated and two fingers (slipped up between the tumour and the sacral promontory) felt the right foot, which was brought down and the membranes ruptured. The case was then left to nature for four hours, and at 10 P.M. Dr. Ebenezer Davies kindly gave chloroform, and I was able to lift the tumour slightly forward and to bring down the left foot and fairly easily to deliver a nearly tull-term living female child. On again passing my hand into the uterus, I felt certain the tumour conld be peeled from the uterine wall, as its connexion with it felt like that of an adherent placenta; so, as the placenta was detached, I kept this in utero with the object of preventing as much as possible uterine contraction, and carefully peeled off the tumour from the anterior lip and adjoining wall of the uterus, to which it was attached for a surface of about three inches in diameter. This was easily effected, except near the margin of the os, where a firm fibrous band had to be cut through after being ligatured. The placenta immediately followed, and the amount of blood lost was not more than usual, and both mother and child did well. On July 24th, 1882, the sound passed the normal length and no evidence of the tumour existed. She did not suckle the child, and menstruation had recurred naturally. In April, 1883, as the result of a fall, she miscarried at the sixth month, giving birth to a male stillborn twin without any assistance, and nothing could then be felt of the pre-existing tumour.

Remarks. - I have thought this case worth reporting, since $I$ believe the treatment adopted is universally condemned. When I consider, however, the frequent pregnancies which occurred with gradually increasing difficulty in effecting delivery, the very careful but ineffectual attempt which I had seen made to remove the tumour with the écraseur, the perfect ease with which I was able to take away the tumour under the altered circumstances, and the entire absence of a subsequent bad symptom, I cannot but think that the end attained jnstified the practice, and that it was right to seize such a favourable opportunity for extirpating the growth.

\section{TUBERCULAR MENINGITIS.}

APIIASIA ; PARALYSIS OF ARM, LEG, FACE, AND TONGUE; CONVULSIONS ; DEATH.

BY MICHAEL COLLINS, M.D., M.CH., Q.U.I., LATELY SENIOR RESIDENT SURGEON, NOTTINGHAM GENERAL DISPENSARY.

J. H March, was taken suddenly ill at the commencement of June of last year. His mother noticed that for some time past he suffered from general malaise and slight loss of flesh, but she did not consult any medical man till the child had "a fit" on June 5th. I saw him soon afterwards, but found no distinctive evidence of serious brain mischief, and merely prescribed a vermifuge powder. Next day he passed a round worm, and soon recovered his usual elasticity of frame and buoyancy of spirits. On June 25th I was asked to see him again, and found him suffering from symptoms referable to tubercular meningitis of the base of the brain-headache, sickness, retracted abdomen, constipation, with a pulse of 120 and a temperature of $101^{\circ} \mathrm{F}$; ; tache cérébrale fairly well marked, cold feet and hands and cold sensation; pupils dilated and acting fairly to light; no ptosis and no paralysis of recti. The cephalalgia was at times intense. His hair was cut off and ice applied, rest and quietness were enjoined; he was ordered light and nutritious food, but no medicine beyond a gentle aperient. Then followed several days of delusive calm. The mother's hopes were buoyed up, but unfortunately they were destined to be rudely shaken on the 31 st, when our little patient had a convulsive seizure which left him suffering from aphasia, paralysis of the right ? rm, right leg, and right side of the face and tongue. The paralysis was well marked in the right arm, face, and tongue; the paresis of the leg was comparatively slight, and soon recovered from. Pulse 130, strong; temperature $101^{\circ} 6^{\circ}$. On August 2nd the pulse was 90 , temperature $101^{\circ}$. The next few days brought slight improvement, till about the $6 \mathrm{tb}$, when pain in the right side with urgent dyspnoea supervened. Physical examination of the chest revealed diminution of normal respiratory sounds at both bases, tubular breathing with well-marked dulness at left apex. The urgent chest symptoms soon disappeared; the dulness remained. By August 10th gradual improvement again set in. Slept well with the exception of occasional startings. He now began to move his right leg well and his arm slightly. But the facial and lingual paralyses were as well marked as ever. He could say " $\mathrm{No"}$ and "Yes." He took nourishment liberally. The cephalalgia was still intense. On August 13th the pulse was 100 , irregular and intermittent. The patient vomited in the afternoon; headache was severe. On the next day the irregularity and intermittency of the pulse had disappeared, and I was unable to detect it again during my subsequent visits. Now set in a final delusive calm, the halo hovering round decay. For a little time he could walk across the room and place his right hand on any part of his head; there was intermission of severe head symptoms; speech did not return. He sat up during the day, slept well, and took his food with manifest relish. On Sept. 15th convulsions set in, lasting for half an hour, and leaving him in an unconscious condition till the following morning. On the 16 th the patient was drowsy but conscious, pupils dilated and almost insensitive. On the 17th convulsions supervened, and death closed the scene.

Unfortunately a post-mortem could not be obtained. It scarcely admits of a doubt that the meninges at the base of the brain were studded with miliary tubercle at first; that these subsequently invaded the cortical motor zone of the left hemisphere, producing hyperæmia and disorganisation, well marked in the lower part of the ascending convolutions and posterior part of the inferior frontal convolutions. The upper part of the ascending convolutions one would expect to find affected in a less degree. The cases reported by Mr. Seymour Sharkey bear out my diagnosis.

A NUMBER of vendors of milk in Birmingham have recently been fined for adulteration with water and abstraction of cream. Although stated to have been sold as received in several instances, the law was brought to bear apon the consignees in the absence of a written guarantee with each lot sent, the railway companies refusing to carry it under lock and key. 